\section{Changes in the Ultrastructure of the Epicuticular Wax and Postharvest Calcium Uptake in Apples}

\author{
Stephane Roy \\ Horticultural Crops Quality Laboratory and Electron Microscope Laboratory, \\ Beltsville Agricultural Research Center, Agricultural Research Service, U.S. \\ Department of Agriculture, Beltsville, MD 20705
}

William S. Conway and Alley E. Watada

Horticultural Crops Quality Laboratory, Beltsville Agricultural Research Center, Agricultural Research Service, U.S. Department of Agriculture, Beltsville, MD 20705

\section{Carl E. Sams}

Department of Plant and Soil Science, The University of Tennessee, Knoxville, TN 37901

\section{Eric F. Erbe and William P. Wergin \\ Electron Microscope Laboratory, Beltsville Agricultural Research Center, Agricultural Research Service, U.S. Department of Agriculture, Beltsville, MD 20705 \\ Additional index words. $\mathrm{CaCl}_{2}$, low-temperature scanning electron microscopy, Malus $\times$ domestica, pressure infiltration}

\begin{abstract}
Structural changes in the cuticle could be partially responsible for the differences in uptake of infiltrated $\mathrm{Ca}$ in apple fruit. We examined the relationship between the surface structure of epicuticular wax of 'Golden Delicious' apple and Ca uptake by the fruit. Apples were nontreated or pressure infiltrated with distilled water, or with 0.14 or 0.27 mol.L ${ }^{-1} \mathrm{CaCl}_{2}$ solutions 2 weeks before optimum harvest time, at optimum harvest, or after 2,4 , or 6 months of storage at $0{ }^{\circ} \mathrm{C}$. Examination of the fruit surface with low-temperature scanning electron microscopy revealed that cracks in the epicuticular wax became wider and deeper as storage duration increased. After 6 months of storage, the cracks extended through the cuticle. Uptake of $\mathrm{Ca}$ by the infiltrated fruit was greater after 6 months of storage than after shorter storage intervals. These data indicate that as storage duration increased, epicuticular wax cracks became deeper and Ca uptake by the fruit increased.
\end{abstract}

Numerous investigations suggest that many physiological and pathological disorders of apples are related to the calcium $(\mathrm{Ca})$ content of their tissues. An adequate concentration of Ca maintains fruit firmness; lowers the incidence of such disorders as water core, bitter pit, and internal breakdown (Bangerth et al., 1972; Faust and Shear, 1968; Reid and Padfield, 1975); and reduces decay caused by postharvest pathogens (Conway et al., 1991). Because the $\mathrm{Ca}$ concentration required to control such disorders is usually higher than can be obtained with fertilization practices, the effects of the direct application of $\mathrm{CaCl}_{2}$ solutions to fruit and the resulting effects on storage quality

\footnotetext{
Received for publication 18 Mar. 1998. Accepted for publication 17 Aug. 1998. We express our appreciation to George A. Brown for valuable technical assistance. Use of a company name or product by the U.S. Dept. of Agriculture does not imply approval or recommendation of the product to the exclusion of others that also may be suitable. The cost of publishing this paper was defrayed in part by the payment of page charges. Under postal regulations, this paper therefore must be hereby marked advertisement solely to indicate this fact.
}

have been investigated (Conway et al., 1991; Glenn and Poovaiah, 1985; Sams and Conway, 1984). Pressure infiltration of fruit with solutions of $\mathrm{CaCl}_{2}$ increases the $\mathrm{Ca}$ concentration more effectively than does spraying, dipping, or vacuum infiltration (Conway and Sams, 1983). However, the mechanisms involved in Ca penetration are poorly understood, and an understanding of these pathways could enhance efforts to infiltrate $\mathrm{Ca}$.

The plant cuticle forms a continuous nonliving, noncellular lipoidal layer that covers most of the aerial portions of a plant, and serves as a protective barrier between the plant and its environment (Bukovac et al., 1981). It prevents uncontrolled loss of water and hinders attack by pathogens and insects. The surface properties of fruit, particularly those of the cuticle, affect the absorption and distribution of applied chemicals. Little is known, however, about the ultrastructural changes occurring in the apple cuticle during storage. Transmission electron microscopy (TEM) (Chafe and Wardrop, 1973; DeVries, 1968) and scanning electron microscopy (SEM) (Baker and Parsons, 1971; Jeffree, 1986; Jeffree et al., 1975; Krause and Cannon, 1991; Krause and Houston, 1983; Skene, 1963) have been used extensively to examine the structure of a wide range of plant surfaces. The images obtained have revealed information about epicuticular wax ultrastructure, but, because the specimens were subjected to chemical fixation, dehydration, and drying, structural artifacts often occurred. For example, dehydration can remove or alter lipids and critical point drying can shrink and distort tissues. Improvements in a technique referred to as low-temperature SEM allow observation of samples in their frozen, hydrated state, thereby avoiding the artifacts associated with other preparation procedures (Wergin and Erbe, 1991a, 1991b, 1992). This technique is particularly valuable because water, which is the major constituent of most biological material and frequently affects the morphology and ultrastructure of tissues, is retained in the frozen tissues (Jeffree and Read, 1991).

In the present study we utilized low-temperature SEM to investigate the surface structure of harvested apple fruit. The structural features of the cuticle were then related to the concentration of $\mathrm{Ca}$ in the fruit following infiltration with $\mathrm{CaCl}_{2}$.

\section{Materials and Methods}

'Golden Delicious' apples were harvested at two different times prior to the climacteric (ethylene evolution $<2 \mathrm{pmol} \cdot \mathrm{kg}^{-1} \cdot \mathrm{s}^{-1}$; the climacteric rise in $\mathrm{CO}_{2}$ production had not yet begun) from a commercial orchard. Care was taken to avoid mechanical damage to the cuticle during harvest, transport, and preparation of the specimens. The first harvest was conducted 2 weeks before the predicted prime harvest period. The fruit were randomized, either left untreated or pressure infiltrated (3 min at $103 \mathrm{kPa}$ ) with distilled water or with 0.14 or $0.27 \mathrm{~mol} \cdot \mathrm{L}^{-1} \mathrm{CaCl}_{2} \cdot 2 \mathrm{H}_{2} \mathrm{O}$ and stored at $0{ }^{\circ} \mathrm{C}$. A second sample of fruit was taken at the prime harvest period. Harvested fruit were randomized and divided into four lots. One lot was immediately treated with $\mathrm{CaCl}_{2}$ solutions as described above, and placed in cold storage along with the three lots of nontreated fruit. At 2-, 4-, and 6-month intervals, one of the remaining nontreated lots of fruit from the prime harvest was removed from storage, warmed to room temperature, treated with $\mathrm{CaCl}_{2}$ solutions as previously described, and placed in cold storage. After 6 months of storage, all fruit were examined for cracks in the epicuticular wax and for tissue Ca content. Sampling times for low-temperature SEM observations paralleled those used for the $\mathrm{Ca}$ analysis.

Fruit tissues were observed in a field emission SEM (Hitachi S-4100; Hitachi Scientific Instruments, Mountain View, Calif.) equipped with a low-temperature stage (Oxford CT1500HF Cryotrans System; Oxford Instruments, Enysham, England). The samples were placed on a standard flat specimen holder as described by Roy et al. (1994). The holder was immediately plunged into liquid nitrogen and cryotransferred under vacuum to the cold stage 


\section{Postharvest Biology \& Technology}

in the prechamber of the cryosystem. To sublime surface water, the frozen specimens were etched by raising the temperature of the stage in the prechamber to $-90{ }^{\circ} \mathrm{C}$ for $8 \mathrm{~min}$. The specimens were then sputter coated with $\mathrm{Pt}$ in the prechamber and transferred to the cryostage in the SEM for observation. The surfaces of four apples were sampled for each treatment.

The Ca content of the tissue was determined by using a mechanical peeler to remove the peel and outer flesh to a depth of $2 \mathrm{~mm}$. This portion was discarded. The peeler was then used to remove the next $2 \mathrm{~mm}$ of flesh, which was used for $\mathrm{Ca}$ analysis. Four samples, each consisting of flesh from five apples, were evaluated for each treatment. The flesh used for $\mathrm{Ca}$ analysis was immediately frozen in liquid nitrogen, freeze-dried, and ground. One gram of tissue from each sample was dryashed, dissolved in $2 \mathrm{~N} \mathrm{HCl}$, and analyzed for Ca content using inductively coupled plasma atomic emission spectrometry (model ICAP 61; Thermo-Jarrell Ash Co., Franklin, Mass.). The Ca concentration is reported on a dry weight basis. Two replicates were analyzed per sample.

The experiment was a factorial arrangement of treatments within a randomized complete-block design. There were five sampling times and four treatments with four random replications of each treatment. There were two subsamples nested within each replicate. The experimental blocks were sampling time and $\mathrm{Ca}$ treatment. The analysis of variance (ANOVA) was performed using procedures of a statistical software package (SAS Institute, 1989).

\section{Results}

Epicuticular waxes appeared relatively smooth and homogenous 2 weeks before prime harvest (Fig. 1A). The cuticle appeared to consist of simple platelets that were organized in parallel layers. However, the wax surface was regularly interrupted by cracks that formed an interconnected network (Fig. 1B). The cracks apparently resulted from the separation of the older wax platelets as the fruit enlarged. No noticeable structural differences were apparent in the cuticular surface of fruit sampled before versus at prime harvest time (data not shown).

In fruit stored for 2 months, the cracks were shallow and extended to a depth of two to three wax platelets (Fig. 2); on those stored for 4 months, the cracks were more numerous (Fig. 3) and extended to a depth of seven to eight layers of platelets. At low magnification, the surface of fruit stored for 6 months did not appear to differ from that of fruit stored for 4 months (Fig. 4A). However, upon closer examination, the cracks appeared to be deeper (Fig. 4B). No obvious variation was observed within any treatment.

The concentration of $\mathrm{Ca}$ in the flesh increased with the concentration of the $\mathrm{CaCl}_{2}$ solution used for infiltration (Fig. 5). ANOVA indicated a significant difference in Ca content among sampling times and $\mathrm{CaCl}_{2}$ concentrations. There was a significant interaction be-

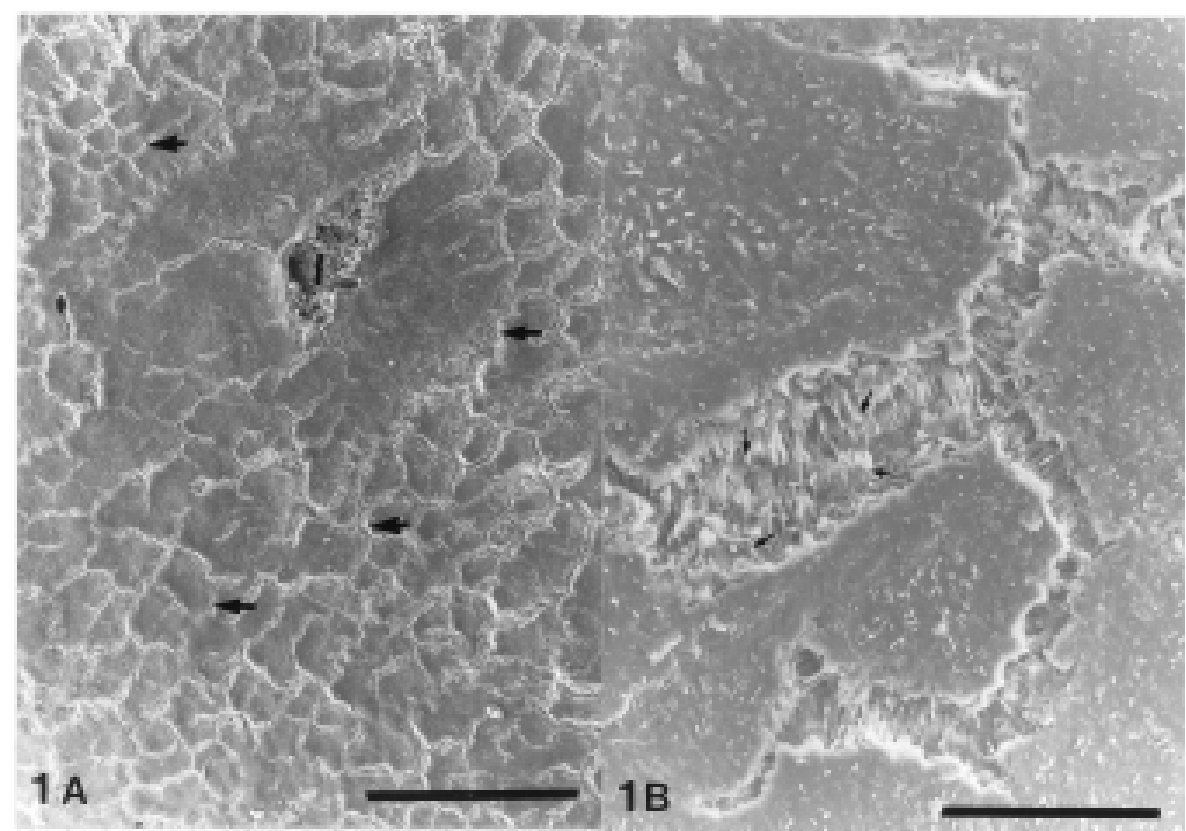

Fig. 1. Low-temperature SEM of epicuticular wax of apple fruit harvested 2 weeks before the predicted prime harvest. (A) General view showing the relatively smooth surface of the fruit and the network of cracks (arrows) on its surface. Bar $=600 \mu \mathrm{m}$. (B) The cracks result when the oldest layers of wax platelets (arrows) begin to separate. A lenticel is also pictured (l). Bar $=60 \mu \mathrm{m}$.

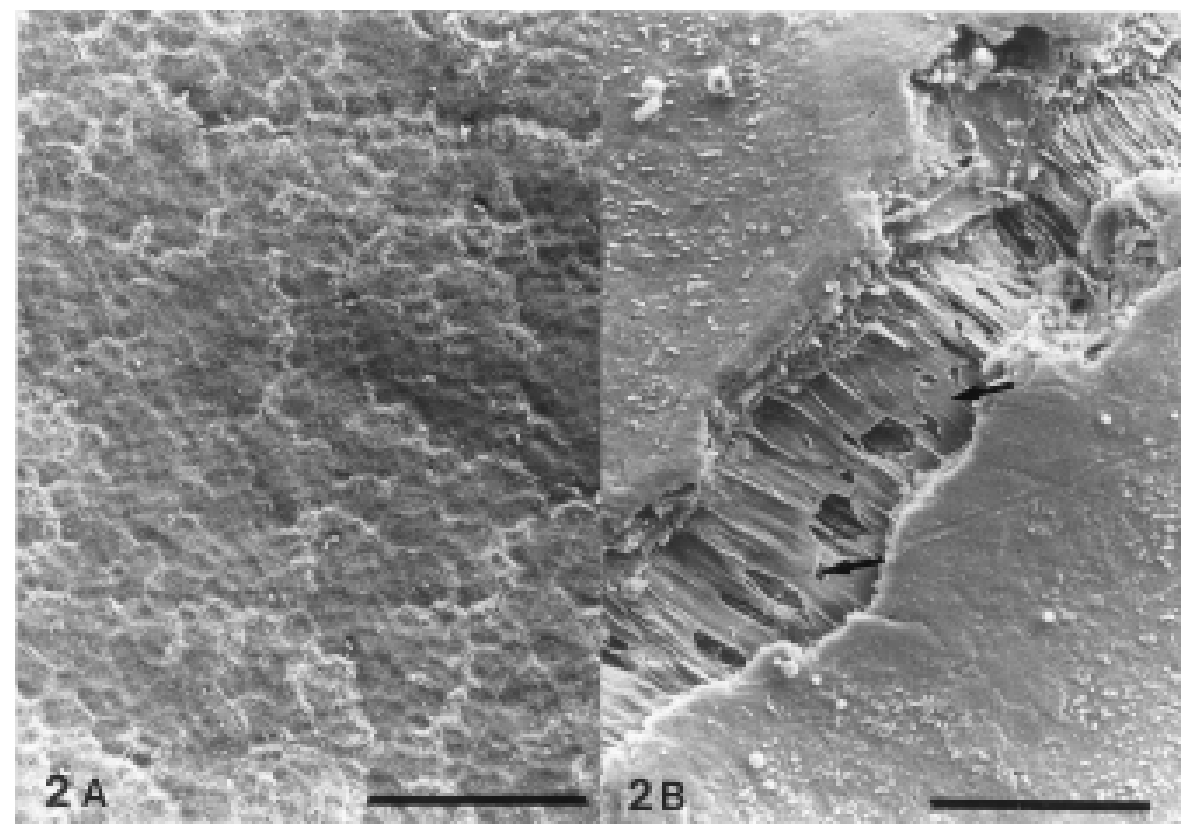

Fig. 2. Low-temperature SEM of epicuticular wax of apple fruit stored for 2 months at $0^{\circ} \mathrm{C}$. (A) General view. Bar $=600 \mu \mathrm{m}$. (B) These cracks are shallow and appear to affect the oldest cuticular layers. Note the fissuration of wax platelets (arrows) that correspond to the opening of the crack. $\mathrm{Bar}=60 \mu \mathrm{m}$.

tween sampling time and $\mathrm{CaCl}_{2}$ concentration. Fruit $\mathrm{Ca}$ content increased with $\mathrm{CaCl}_{2}$ content of the infiltration solution. For both $\mathrm{CaCl}_{2}$ concentrations, the time of treatment affected uptake. Flesh Ca concentrations were similar whether fruit were infiltrated 2 weeks before harvest, at harvest, or 2 months after harvest. However, Ca content increased nearly linearly with time in storage when the fruit were treated after 2 months of storage. The greatest increase in apple flesh $\mathrm{Ca}$ concentration occurred in fruit infiltrated with $\mathrm{CaCl}_{2}$ solutions after 6 months of storage.

\section{Discussion}

The general advantages of cryofixation and low-temperature SEM observation, as opposed to the conventional SEM preparation techniques, have been discussed previously (Wergin and Erbe, 1989, 1991b, 1992). For the critical examination of epicuticular waxes, low-temperature SEM currently seems to be the best method available (Jeffree and Read, 1991; Read and Jeffree, 1991). Low-temperature SEM avoids mechanical damage during chemical processing (Guggenheim et al., 1991; 


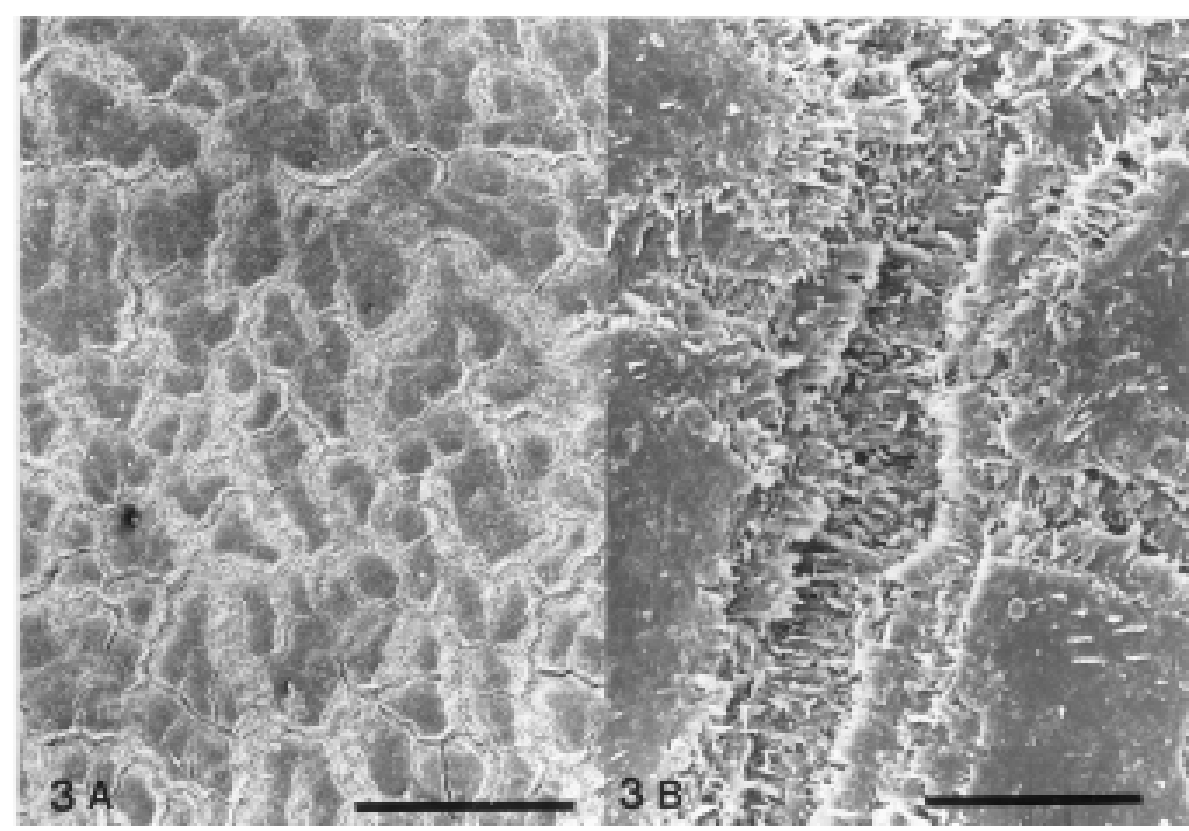

Fig. 3. Low-temperature SEM of epicuticular wax of apple fruit stored for 4 months at $0{ }^{\circ} \mathrm{C}$. (A) General view showing an extended network of cracks. Bar $=600 \mu \mathrm{m}$. (B) Enlarged cracks that completely separate the first three layers of wax platelets. Bar $=60 \mu \mathrm{m}$.

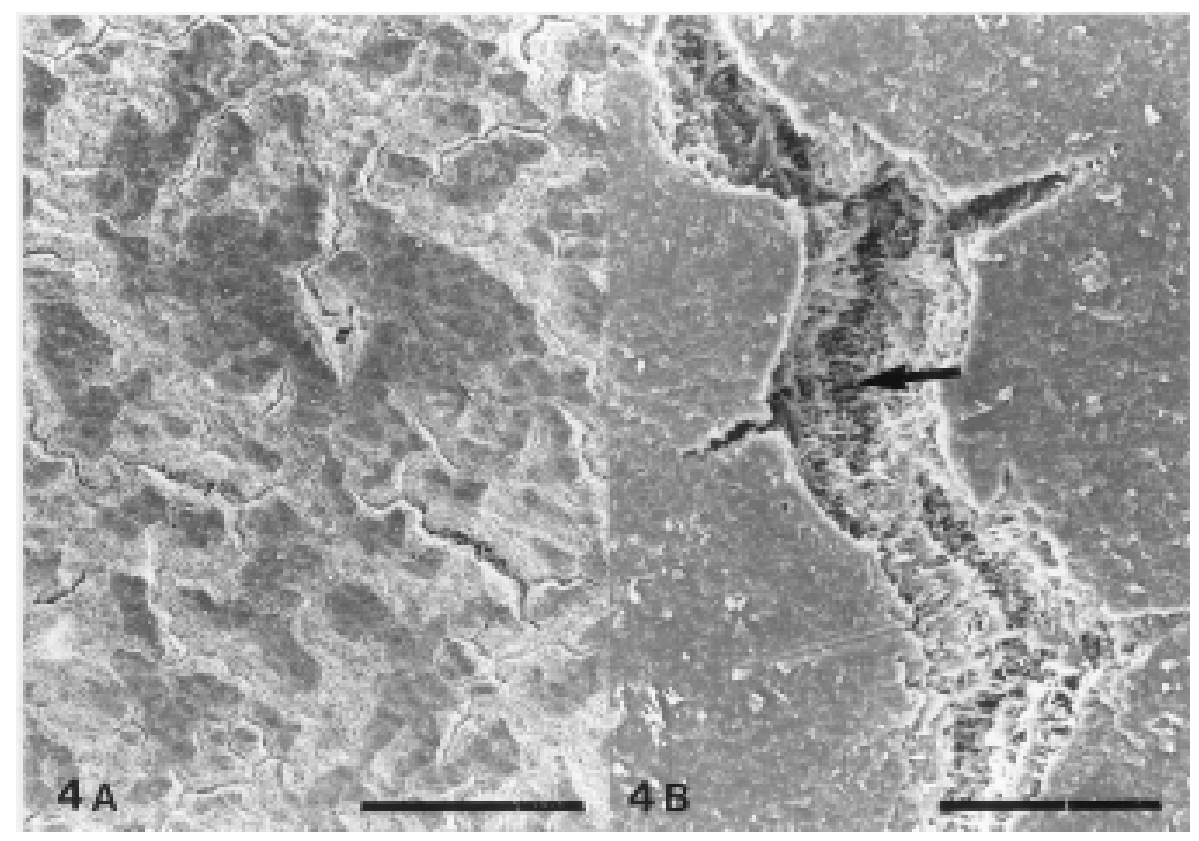

Fig. 4. Low-temperature SEM of epicuticular wax of apple fruit stored for 6 months at $0{ }^{\circ} \mathrm{C}$. (A) General view. Bar $=600 \mu \mathrm{m}$. (B) The cracks have deepened and widened. The separation of several layers of platelets appears to reveal the underlying cell wall (arrow). Bar $=60 \mu \mathrm{m}$.

Jeffree and Sandford, 1982; Van Gardinen et al., 1989) and retains the structure of wax platelets that could have been altered or removed by solvents during conventional dehydration (Jeffree and Sandford, 1982; Pitcairn et al., 1986; Roy et al., 1994; Scheidegger et al., 1991).

During postharvest treatment of apples with $\mathrm{CaCl}_{2}$ solutions, $\mathrm{Ca}$ probably enters the fruit primarily through the lenticels (Betts and Bramlage, 1977), but cracks in the cuticle and epidermis may also be important pathways (Glenn et al., 1985). Such cracks are especially prevalent in 'Golden Delicious' fruit early in the growing season, and increase in width and number as the fruit enlarge and mature (Meyer, 1944). At maturity, the cracks on the surface of the fruit are larger and form a network (Faust and Shear, 1972). Studies on cuticle permeability to $\mathrm{CaCl}_{2}$ solutions indicated that both permeability and the number of cracks in the cuticle increased as fruit developed (Glenn et al., 1985). The development of cracks and other surface irregularities during the latter part of the growing season may play a significant role in Ca penetration into the apple fruit.
Our results indicate that cracking in the epicuticular wax layers and the subtending cuticular layers of apple fruit not only increased as the growing season progressed, but the width and depth of the cracks continued to increase during cold storage. The amounts of $\mathrm{CaCl}_{2}$ solution taken into the fruit increased with time in storage. Although more $\mathrm{CaCl}_{2}$ solution entered the fruit when infiltrated after 6 months in storage rather than at harvest, the deleterious physiological and pathological processes that $\mathrm{Ca}$ would prevent had already occurred. Therefore, $\mathrm{Ca}$ infiltration as soon after harvest as possible is still advisable.

This study was not intended to explain the tendency of apples to crack, which has been studied by numerous authors (DeVries, 1968; Skene, 1963; Verner, 1938), but to relate cracking to Ca uptake. We were surprised to observe a high degree of epicuticular cracking after 6 months in storage. Fruit growth and development cause expansion of the pericarp tissues and expansion of the skin. These processes increase the distance between platelets and produce cracks. However, this phenomenon does not explain why cracks continue to develop after 6 months of storage, although the loss of fruit moisture may be responsible.

The positive correlations observed between the increase in Ca content of apple fruit and the development of cracks in the epicuticular wax is now well established and support the results of prior studies that related cracking in the cuticle to Ca uptake. Previously, we showed that heat treatment obstructs the cracks and thus reduces uptake of $\mathrm{Ca}$ by the fruit (Roy et al., 1995). These studies suggest that the cracks in the epicuticular wax provide a pathway through which the Ca solutions can penetrate into the fruit tissues. The increases in cracking may also be related to decay caused by pathogens during storage, as the barrier between the fruit and the environment deteriorates.

\section{Literature Cited}

Baker, E.A. and E. Parsons. 1971. Scanning electron microscopy of plant cuticles. J. Microscopy 94:39-49.

Bangerth, F., D.R. Dilley, and D.H. Dewey. 1972. Effect of postharvest calcium treatments on internal breakdown and respiration of apple fruits. J. Amer. Soc. Hort. Sci. 97:679-682.

Betts, J.A. and W.J. Bramlage. 1977. Uptake of calcium by apples from postharvest dips in calcium chloride solutions. J. Amer. Soc. Hort. Sci. 102:785-788

Bukovac, M.J., H.P. Rasmussen, and V.E. Shull. 1981. The cuticle: surface, structure and function. Scanning Electron Microscopy 1981; III:213-223.

Chafe, S.C. and A.B. Wardrop. 1973. Fine structural observations on the epidermis. II. The cuticle. Planta 109:39-48.

Conway, W.S. and C. Sams. 1983. Calcium infiltration of 'Golden Delicious' apples and its effect on decay. Phytopathology 73:1068-1071.

Conway, W.S., C.E. Sams, J.A. Abbott, and B.D. Bruton. 1991. Postharvest calcium treatment of apple fruit to provide broad-spectrum protection against postharvest pathogens. Plant Dis. 75:620622 . 


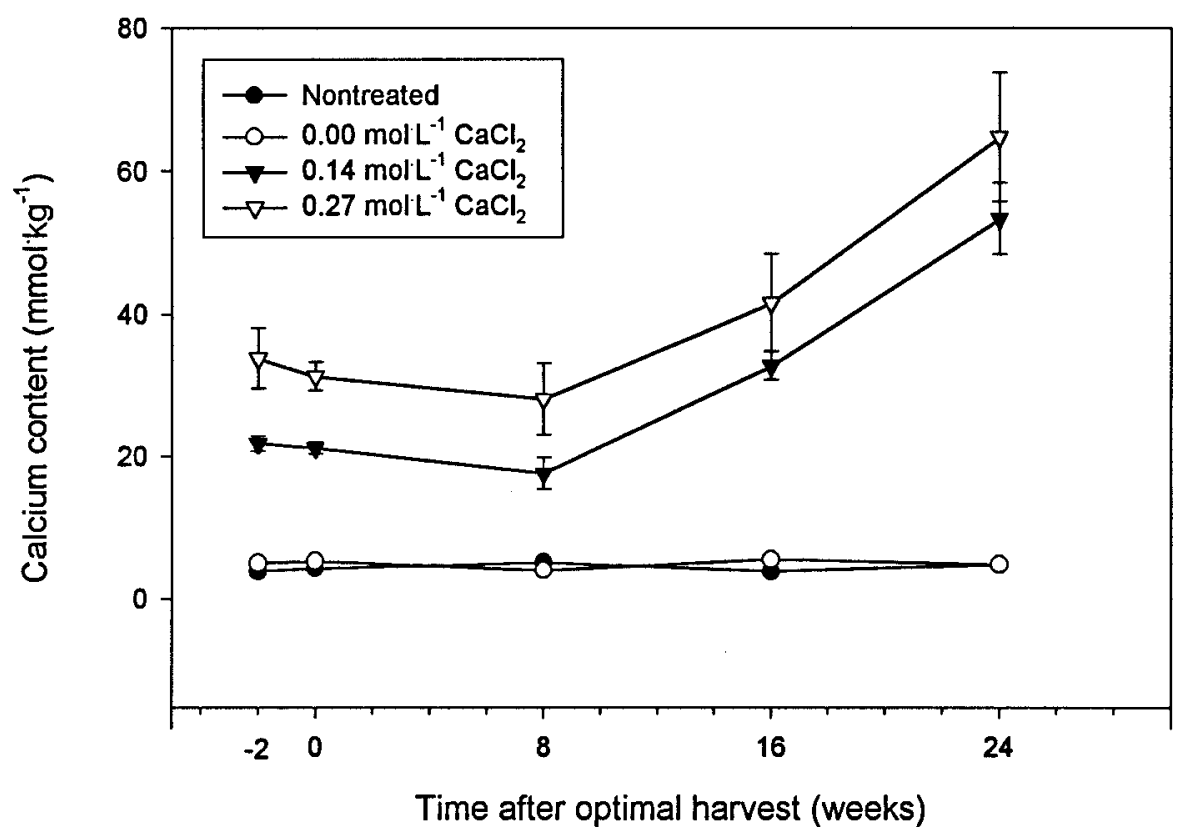

Fig. 5. Calcium concentration (dry weight basis) of the flesh of 'Golden Delicious' apple fruit as affected by infiltration with $0 \%, 2 \%$, or $4 \%$ solutions of $\mathrm{CaCl}_{2} 2$ weeks before the predicted prime harvest, at prime harvest, and after 2,4 , or 6 months of storage at $0^{\circ} \mathrm{C}$. Vertical bars indicate standard errors of the means (SE).

DeVries, H.A. M.A. 1968. Development of the structure of the normal smooth cuticle of the apple 'Golden Delicious'. Acta Bot. Neerl. 17:229-241.

Faust, M.. and C.B. Shear. 1968. Corking disorders of apples: A physiological and biochemical review. Bot. Rev. 34:411-469.

Faust, M. and C.B. Shear. 1972. Fine structure of the fruit surface of three apple cultivars. J. Amer. Soc. Hort. Sci. 97:351-355.

Glenn, G.M. and B.W. Poovaiah. 1985. Cuticular permeability to calcium compounds in 'Golden Delicious' apple fruit. J. Amer. Soc. Hort. Sci. 110:166-171.

Guggenheim, R., M. Duggelin, D. Mathys, and C. Grabski. 1991. Low-temperature SEM for detection of fungicide activity. J. Microscopy 161:337-342.

Jeffree, C.E. 1986. The cuticle, epicuticular waxes and trichomes of plants, with reference to their structure, functions and evolution, p. 23-64. In: B.E. Juniper and R. Southwood (eds.). Insects and plant surfaces. Edward Arnold, London.

Jeffree, C.E., E.A. Baker, and P.J. Holloway. 1975.
Ultrastructure and recrystallization of plant epicuticular waxes. New Phytol. 75:539-549. low-temperature scanning electron microscopy, p. 313-414. In: J.L. Hall and C. Hawes (eds.). Electron microscopy of plant cells. Academic, London.

Jeffree, C.E. and A.P. Sandford. 1982. Crystalline structure of plant epicuticular waxes demonstrated by cryostage scanning electron microscopy. New Phytol. 91:549-559.

Krause, C.R. and W.N. Cannon, Jr. 1991.Epistomatal wax injury to red spruce needles (Picea rubens Sarg.) grown in elevated levels of ozone and acidified rains. Scanning Microscopy 5:11731180.

Krause, C.R. and D.B. Houston. 1983. Morphological variation in epicuticular wax of $\mathrm{SO}_{2}$-sensitive and -tolerant eastern white pine clones.

Meyer, A. 1944. A study of the skin structure of 'Golden Delicious' apples. Proc. Amer. Soc. Hort. Sci. 45:723-727.

Pitcairn, C.E.R., C.E. Jeffree, and J. Grace. 1986.
Jeffree, C.E. and N.D. Read. 1991. Ambient and Phytopathology 73:1266-1269.
Influence of polishing and abrasion of the leaf surface of Festuca arundinaceae Schreb. Plant Cell Environ. 9:191-196.

Read, N.D. and C.E. Jeffree. 1991. Low-temperature scanning electron microscopy in biology. J. Microscopy 161:59-72.

Reid, M.S. and C.A.S. Padfield. 1975. Control of bitter pit in apples with lecithin and calcium. N.Z. J. Expt. Agr. 7:379-381.

Roy, S., A.E. Watada, W.S. Conway, E.F. Erbe, and W.P. Wergin. 1994. Low-temperature scanning electron microscopy of frozen hydrated apple tissues and surface organs. HortScience 29:305-309.

Roy, S., W.S. Conway, A.E. Watada, C.E. Sams, E.F. Erbe, and W.P. Wergin. 1995. Heat treatment affects epicuticular wax structure and postharvest calcium uptake in 'Golden Delicious' apples. HortScience 29:1056-1058.

Sams, C.E. and W.S. Conway. 1984. Effect of calcium infiltration on ethylene production, respiration rate, soluble polyuronide content, and quality of 'Golden Delicious' apple fruit. J. Amer. Soc. Hort. Sci. 109:53-57.

SAS Institute. 1989. SAS user's guide: Version 5 SAS Inst., Cary, N.C.

Scheidegger, C., M. Gunthardt-Goerg, R. Matyssek, and P. Hatvani. 1991. Low-temperature scanning electron microscopy of birch leaves after exposure to ozone. J. Microscopy 161:85-95.

Skene, D.S. 1963. The fine structure of apple, pear, and plum fruit surfaces, their changes during ripening, and their response to polishing. Ann. Bot. 27:581-587.

Van Gardingen, P.R., C.E. Jeffree, and J. Grace 1989. Variation in stomatal aperture in leaves of Avena fatua $\mathrm{L}$. observed by low-temperature scanning electron microscopy. Plant Cell Environ. 12:887-898.

Verner, L. 1938. Histology of apple fruit tissue in relation to cracking. J. Agr. Res. 57:813-824.

Wergin, W.P. and E.F. Erbe. 1989. Increasing the versatility of an Emscope SP2000A Sputter Cryo System on a Hitachi S-570 scanning electron microscope. Scanning 11:293-303.

Wergin, W.P. and E.F. Erbe. 1991a. Increasing resolution and versatility in low temperature conventional and field emission scanning electron microscopy. Scanning Microscopy 5:927936.

Wergin, W.P. and E.F. Erbe. 1991b. Introduction to the advantages and problems associated with low temperature scanning electron microscopy. Scanning 13:14-26.

Wergin, W.P. and E.F. Erbe. 1992. Recent advances in low temperature scanning electron microscopy. Supplement to Scanning 14:40-42. 